\title{
Role OF PI3K/AKt PathWay in Protection of ISONIAZID/RIFAMPICIN-INDUCED HEPATOTOXICITY: A Pharmacological Approach
}

\author{
Gaurav Gupta ${ }^{1 *}$, Anurag Mishra ${ }^{2}$, Sachchidanand Pathak ${ }^{1}$, Santosh Kumar Singh ${ }^{3}$, \\ Himmat Singh ${ }^{3}$ and Rajiv Dahiya ${ }^{4}$ \\ ${ }^{1}$ Department of Pharmacology, School of Pharmacy, Suresh Gyan Vihar University, Jagatpura, \\ Jaipur-302017, Rajasthan, India \\ ${ }^{2}$ Department of Pharmaceutical Analysis, NIMS Institute of Pharmacy, NIMS University, \\ Jaipur-303121, Rajasthan, India \\ ${ }^{3}$ Department of Pharmaceutics, School of Pharmacy, Suresh Gyan Vihar University, Jagatpura, \\ Jaipur-302017, Rajasthan, India \\ ${ }^{4}$ School of Pharmacy, Faculty of Medical Sciences, The University of the West Indies, St. Augustine, \\ Trinidad \& Tobago, West Indies \\ *E-mail: gauravpharma25@gmail.com \\ Tel.: +91 7014790412 .
}

Received: Apr 30, 2021 / Revised: May 05, 2021 / Accepted: May 06, 2021

Drug-induced liver injury is a problem of increasing significance but has been a long-standing concern in the treatment of tuberculosis (TB). This study assessed the hepatoprotective effect of wortmannin, PI3K / Akt / mTOR inhibitor, on experimental induced isoniazid (INH) and rifampicin (RFP) hepatotoxicity in rats. Rats were given INH / RFP (50 mg / kg, orally; 21 days), followed by wortmannin ( $2 \mathrm{mg} / \mathrm{kg}$, orally; 21 days). Final levels of liver enzymes - aspartate aminotransferase (AST), alanine transaminase (ALT), alkaline phosphatase (ALP), lipid peroxidation, antioxidant enzymes - superoxide dismutase (SOD), catalase (CAT), glutathione peroxidase (GPX), glutathione-stransferase (GST), glutathione (GSH), and inflammatory mediators - interleukin-1 beta (IL-1 $\beta$ ), tumor necrosis factor-alpha (TNF- $\alpha$ ), interleukin-6 (IL-6) and wortmannin significantly reduces oxidative stress and inflammation due to INH / RFP-induced liver damage ( $<0.001)$. Wortmannin modifies PI3K / Akt protein expression and Nrf2 / HO-1 on INH / RFP-induced toxicity in Western blot analysis. Histopathology (H\&E) data provide evidence for the protective effect of wortmannin on INH / RFP damage to rat liver tissue. In conclusion, the protective effect of wortmannin, a PI3K / Akt / mTOR inhibitor, against INH / RFP-induced liver injury is achieved by inhibiting the PI3K / Akt / Nrf2 / H0-1 pathway oxidative stress and inflammation.

Key words: INH/RFP, Wortmannin, Hepatotoxicity, PI3K/Akt, Nrf2/HO-1.

\section{INTRODUCTION}

TB is a major infectious disease that kills nearly 2 million people each year. Tuberculosis ranks seventh among all diseases. Isoniazid (INH) and rifampicin (RFP) are the two main rules currently used to treat tuberculosis, and they last from 4 to 6 months and cause toxicity in the liver. When INH and RFP are used together, liver failure occurs. The prevalence of hepatotoxicity in India is $11.6 \%$, while in Western countries it is $4.3 \%$. Hepatotoxicity induced by anti-TB drugs ranges from an uncertain increase in 
transaminases to liver failure. Hepatic impairment is caused by the synergistic effect of INH and RFP [1,2]. Therefore, mechanisms involved in INH / RFP-induced hepatotoxic disease events include oxidative stress, inflammation, and apoptosis. The involvement of inflammatory and apoptotic pathways has been shown to cause hepatotoxicity, i.e. NF-k $\beta$ and PI3K / Akt. It is the regulator of antioxidant cellular defense genes, which stimulates the lower genetic activation of antioxidant enzymes such as HO-1. Nrf2 / HO-1 activation has been used in animal studies in previous studies to demonstrate mechanisms of liver protection against chemically-induced liver damage. Activation and regulation of these pathways can inhibit the pathogenic production of INH / RFPinduced hepatotoxicity [3-5].

In this study, we validated and amplified previous results by demonstrating that INH and RIF-induced hepatotoxicity were correlated with the PI3K / Akt pathway. Using the PI3K / Akt / mTOR inhibitor wortmannin, we expanded the previous study by examining the effects of RIFinduced pathogenic INH and PI3K / Akt / mTOR signaling on the liver and its morphology.

\section{MATERIALS AND METHODS Experimental protocol}

4-6-week-old male Sprague-Dawley rat (150$180 \mathrm{~g})$ were placed in a group in plastic cages, each group of six $(n=6)$ rat, in a light / dark cycle of $24 \pm 2{ }^{\circ} \mathrm{C}$, holded for $1-12 \mathrm{~h}$, adjusted to fit the experiment the week before. Animals are allowed to receive standard food pellets and free drinking water. Animals were selected/utilized following the international standards and policies of the National Institute of Health and the guidelines established by the Ethics Committee of Suresh Gyan Vihar University, Jaipur, Rajasthan in India.

Rats were divided into three groups for experimental approaches. Group I (general control group); Group II (INH / RFP 50 mg / kg for treatment form); Group III (should be $2 \mathrm{mg} /$ $\mathrm{kg}+\mathrm{INH} /$ RFP $50 \mathrm{mg} / \mathrm{kg}$ ). All Group II and Group III drugs were administered orally with a $0.5 \%$ aqueous solution of Tween 80 for 21 days, while Group I mice were administered orally with an aqueous solution of Tween 80, over 21 days with a single dose of 80 to $0.5 \%$ for 21 days. On the $22^{\text {nd }}$ day, the animals were killed with $3 \%$ isofluorane under anesthesia and liver tissue and blood samples were collected. Liver samples were homogenized in phosphate buffer saline
(PBS, pH 7.4) and centrifuged (12,000 g, $10 \mathrm{~min}$, $4{ }^{\circ} \mathrm{C}$ ). The serum was obtained by centrifugation of a blood sample $\left(1000 \mathrm{~g}, 4^{\circ} \mathrm{C}, 10 \mathrm{~min}\right)$ and stored at $80^{\circ} \mathrm{C}$ for further biochemical analysis. The liver component of all groups was stabilized at neutral $10 \%$ formaldehyde.

\section{Biochemical analysis of liver enzymes and pro- inflammatory markers}

Serum levels of ALT, AST and ALP were measured using a blood liver marker colorimetric assay kit according to the standard method provided by the manufacturer. Serum inflammatory cytokine levels of TNF- $\alpha$, IL- $1 \beta$, and IL- 6 were analyzed using the commercially available diagnostic ELISA kit according to the manufacturer's protocol [6].

\section{Biochemical analysis of hepatic oxidative stress markers}

The liver tissue supernatant was used to determine the levels of lipid peroxidation (MDA structure), GSH, antioxidant enzymes (GPx, CAT, GST, SOD) in the role of INH / RFP-induced hepatotoxicity and file. Oxidation pressure marker was determined using the standard colorimetric test kit according to the procedures provided by the manufacturer. Unit of measure was $\mathrm{nmol} / \mathrm{mg}$ protein for MDA and GSH, unit of measure unit/mg protein for GPx, SOD, CAT, and GST [7].

\section{Western blot analysis}

The liver tissue was homogenized in a RIPA buffer with a mixture of protease inhibitors and centrifuge $\left(12,000 \mathrm{~g}, 10 \mathrm{~min}, 4^{\circ} \mathrm{C}\right)$. The obtained supernatant BCA was used to measure ration itself as protein using the protein assay kit. Same amount of protein samples were separated by SDS-PAGE, transferred into a PVDF layer and fixed with 5\% skimmed milk and PI3K (1: 500), PI3K (1: 500), a basic antibody with ACT (1: 500) (1: 1000), nuclear NRF2 (1: 1000), HO-1 (1: 1000), $\beta$-actin (1: 5000), followed by HRP conjugated secondary antibody and rabbit antibody (1: 5000). Immunofluorescence was visualized with an improved chemical surface (ECL, ThermoScientific, USA) and measured by Image J Software (National Institute of Health, USA) [8].

\section{Histopathological analysis}

Sections of the liver settled with formaldehyde were dried in an automated tissue processor, embedded in paraffin, cut to a thickness of $5 \mathrm{~m}$, 
stained with hematoxylin and eosin (H\&E), and then optically microscopically examined with a digital camera (Olympus BX-60, Tokyo, Japan). Experimental group Pathological changes were observed, confirmed, and evaluated by unknown blind pathologists.

\section{Statistical analysis}

The data is presented as the average \pm SD of six animals analyzed by GraphPad Prism 6.0 software. Differences between groups were analyzed by one-way analysis of diversity and later by a multiple comparison test conducted by Bonferroni. A significant difference was confirmed with $\mathrm{P}<0.05$.

\section{RESULTS}

\section{Effect of Wort on INH/RFP-induced liver enzymes}

Compared with normal mice, the liver enzymes AST, ALT, and ALP in the serum of INH / RFPinduced mice were significantly increased ( $P$ $<0.001$ ). Compared with the normal group, the levels of AST, ALT, and ALP in the INH / RFP treatment group alone increased nearly twice $(\mathrm{p}$ $<0.001$ ). Compared with INH / RFP-induced mice, the serum ALT, AST, and ALP levels of mice pretreated with barley were reduced $(\mathrm{P}<0.001)$. The result is shown in Figure 1.

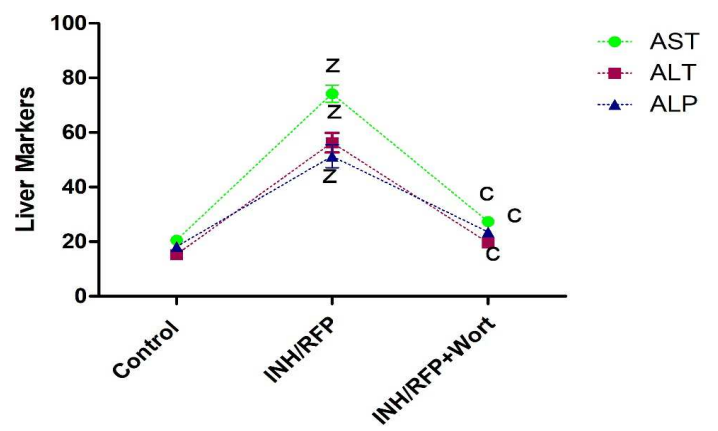

Fig. 1. Effect of Wort on liver enzymes in INH/RFP-induced rats. Data were shown as mean $\pm \operatorname{SD} \quad(n=6)$. " $\mathrm{z}$ " represents statistical difference $(p<0.001)$ from normal group I, and 'c' from INH/RFP-induced group II.

\section{Effect of Wort on INH/RFP-induced inflammatory cytokines}

In ELISA, inflammatory-activating cytokines TNF- $\alpha$, IL-1 $\beta$, and IL-6 levels in INH / RFPinduced mice were found to be significantly increased by $96 \%, 48 \%$, and $59 \%$ ( $p<0.001$ ), respectively. The results were compared with normal control mice. Serum levels from the plant pre-treatment group significantly inhibited TNF$\alpha$, IL-1 $\beta$, and IL-6 ( $p<0.001)$ levels. The result is shown in Figure 2.

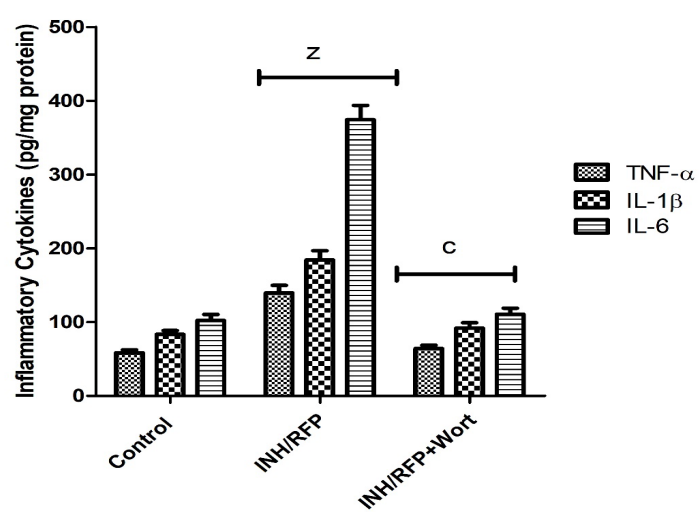

Fig. 2. Effect of Wort on INH/RFP-induced proinflammatory cytokines. Data were shown as mean $\pm S D \quad(n=6)$. ' $z$ ' represents statistical difference $(p<0.001)$ from normal group I, whereas ' $c$ ' represents statistical difference $(p<0.001)$ from INH/RFP -induced group II.

\section{Effect of Wort on INH/RFP -induced oxidative stress markers}

Oxidative stress markers of GSH, SOD, CAT, GPx, and GST were reduced by $27 \%, 52 \%, 33 \%, 39 \%$, and $31 \%$, respectively ( $\mathrm{p}<0.001$ ), and MDA levels by $80 \%(\mathrm{p}<0.001)$ compared to normal control mice INH / in rats induced by RFP). It must retain the activity of $68 \%, 62 \%, 58 \%$, and $43 \%$ of the antioxidant enzymes SOD, GPx, CAT, and GST (p <0.001). Furthermore, wort treatment increased GSH levels by $43 \%$ (P $<0.001$ ) compared to INH / RFP-induced mice, while MDA levels decreased by $46 \%(\mathrm{P}<0.001)$ as shown in Table 1.

Table 1. Effect of wort on INH/RFP-induced MDA, GSH and antioxidant enzymes in rats

\begin{tabular}{|c|c|c|c|c|c|c|}
\hline Treatment & $\begin{array}{c}\text { MDA } \\
\text { (nmol/mg } \\
\text { protein) }\end{array}$ & $\begin{array}{c}\text { GSH } \\
\text { (nmol/mg } \\
\text { protein) }\end{array}$ & $\begin{array}{c}\text { CAT } \\
\text { (U/mg } \\
\text { protein) }\end{array}$ & $\begin{array}{c}\text { SOD } \\
\text { (U/mg } \\
\text { protein) }\end{array}$ & $\begin{array}{c}\text { GPx } \\
\text { (U/mg } \\
\text { protein) }\end{array}$ & $\begin{array}{c}\text { GST } \\
\text { (U/mg } \\
\text { protein) }\end{array}$ \\
\hline Control & $9.36 \pm 0.94$ & $74.39 \pm 4.28$ & $29.47 \pm 1.62$ & $64.37 \pm 5.47$ & $83.27 \pm 6.72$ & $97.37 \pm 7.37$ \\
\hline INH/RFP & $16.32 \pm 1.57^{\mathrm{z}}$ & $52.84 \pm 3.25^{\mathrm{z}}$ & $14.37 \pm 0.95^{\mathrm{z}}$ & $38.95 \pm 1.73^{\mathrm{z}}$ & $47.26 \pm 2.84^{\mathrm{z}}$ & $63.28 \pm 4.38^{\mathrm{z}}$ \\
\hline $\mathrm{INH} / \mathrm{RFP}+$ Wort & $9.93 \pm 0.79^{\mathrm{c}}$ & $68.83 \pm 5.47^{\mathrm{c}}$ & $27.04 \pm 1.57^{\mathrm{c}}$ & $60.04 \pm 4.39^{\mathrm{c}}$ & $78.93 \pm 5.96^{\mathrm{c}}$ & $92.83 \pm 5.28^{\mathrm{c}}$ \\
\hline
\end{tabular}

Data were shown as mean \pm SD $(n=6)$. ' $z$ ' represents statistical difference $(p<0.001)$ from normal group I, whereas ' $c$ ' represents statistical difference $(\mathrm{p}<0.001)$ from INH/RFP -induced group II. 


\section{Effect of wort on INH/RFP-induced protein expressions}

The results of the Western Blot analysis showed that protein expression levels of phosphorescent PI3K, phosphorescent ACT, nuclear Nrf2 and HO1 in INH / RFP-induced mice were approximately 0.5 -fold lower than in the normal

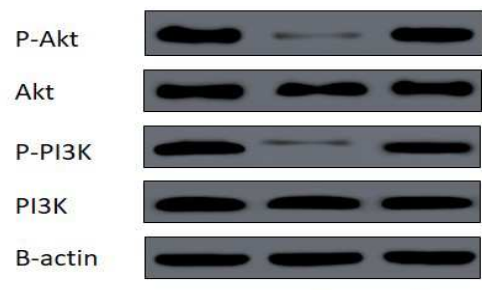

Control INH/RFP INH/RFP +wort
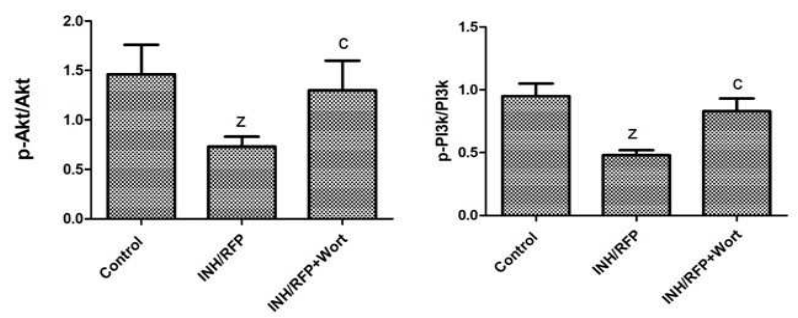

control group $(\mathrm{P}<0.001)$. Compared with the INH / RFP induction group, the protein expression of the phosphorescent PI3K, ACT phosphorylation, Nrf2, and nuclear HO-1 in the barley treatment group increased approximately 1.5-2 times $(\mathrm{P}<0.001)$. The result is shown in Figure 3.
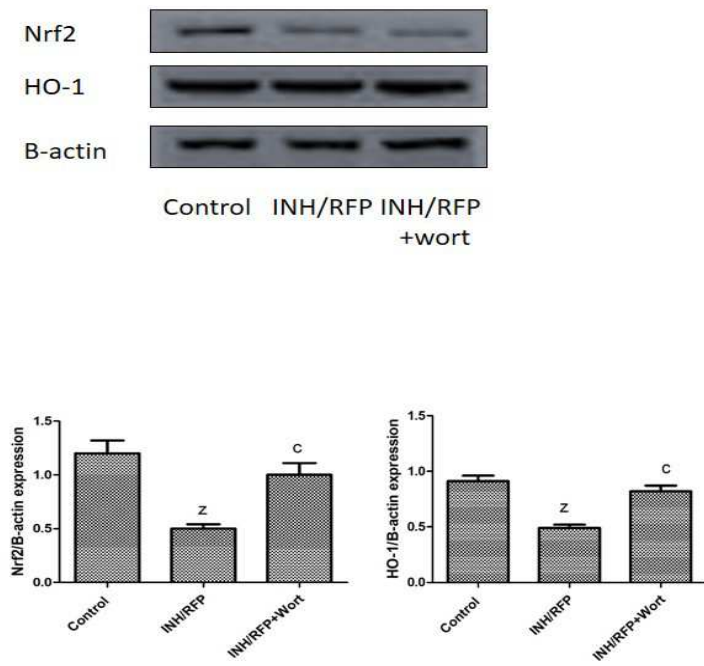

Fig. 3. Effect of wort on PI3K/Akt and Nrf2 signaling pathways in INH/RFP-induced rats. Protein expressions of PI3K, Akt, nuclear Nrf2 and HO- 1 were measured using western blot analysis and $\beta$ actin was used as loading control. Data were shown as mean $\pm S D(n=6)$. ' $z$ ' represents statistical difference $(p<0.001)$ from normal group I, whereas ' $c$ ' represents statistical difference $(p<0.001)$ from INH/RFP-induced group II.

\section{Effect of wort on INH/RFP-induced histopathological changes}

The effect of INH / RFP on hepatocyte morphology has been observed in H\&E stains of liver segments. In the normal group of mice, hepatocytes were observed to have a normal sinusoidal curve, complete nucleation, and normal arrangement of healthy cell structures. In many cases, significant loss of cell boundaries, inflammatory cell infiltration, dilated sinusitis, and vascular cytoplasm was observed in INH / RFP-induced mice. Pre-treatment of aloe hepatocyte alignment significantly maintains the sinusoidal space, limits the infiltration of inflammatory cells, and reduces structural damage to hepatocytes, as shown in Figure 4.

\section{DISCUSSION}

The liver is an important organ for metabolic and functional nutrient storage. Moreover, the liver is an important organ for the detoxification of vital organisms. In most countries of the world, severe liver injury caused by drugs is a worrying condition. Xenobiotics synthesized in the liver undergo biotransformation through cytochrome $\mathrm{P} 450$ isoforms to form reactive oxygen species (ROS), which are harmful to liver cells. INH / RFP-related liver injury is induced by free radicals, or in other words, due to the pathogenesis of oxidative stress during a biological transformation of the drug. When it comes to treating conditions caused by oxidative stress, antioxidants have become a preferred option $[9,10]$. Wortmannin has been reported to have antioxidant and anti-inflammatory effects, supporting the efficacy of the compound in this study. Test for severe poisoning with rats has been reported to show no toxicity or mortality at $400 \mathrm{mg} / \mathrm{kg}$, so only wortmannin at $2 \mathrm{mg} / \mathrm{kg}$ can be considered non-toxic to rats.

An important antioxidant effect is preventing lipid peroxidation against induced oxidative stress. Reactive oxygen species that cause lipid oxidation lead to the formation of 4-HNE, which in turn leads to the inflammatory response and other related pathways. 4-HNE and PGE2 biomarkers and mediators of inflammation, which are clearly expressed in INH / RFP- 

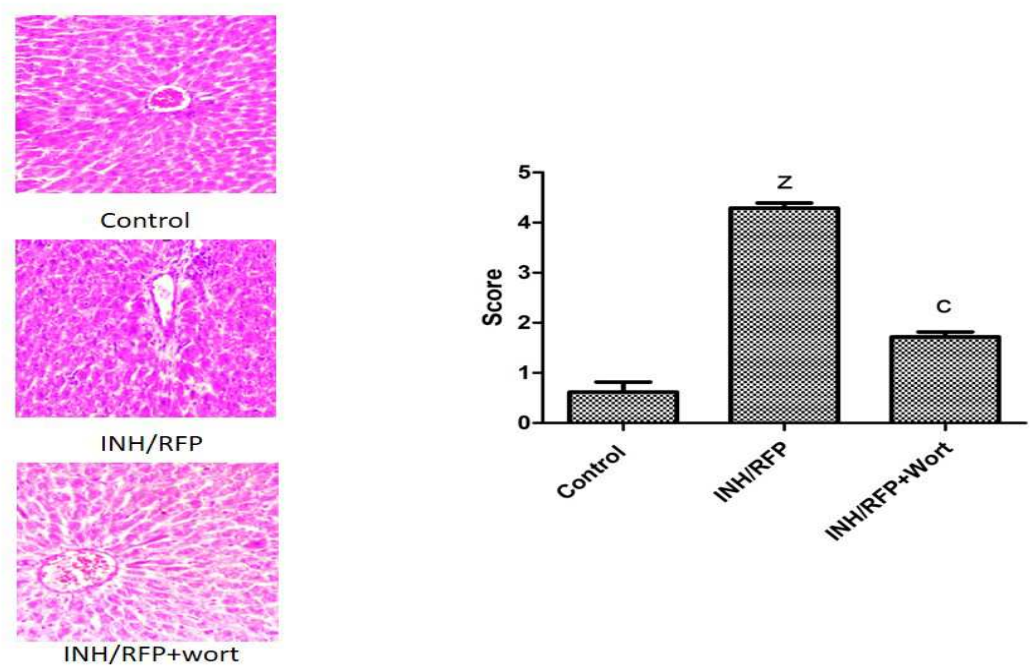

Fig. 4. Effect of wort on histopathological changes in INH/RFP-induced rats. Injury scores were given by a blinded pathologist on a scale of $0-4 ; 0=$ no changes, $1=$ mild changes, $2=$ moderate pathological changes, 3 = bad injury and pathological changes, $4=$ severe injury and inflammation. Black arrows indicate damaged hepatocytes due to necrosis/apoptosis, infiltration of inflammatory cells, and dilated sinusoids. Data were shown as mean $\pm S D(n=6)$. ' $\mathrm{z}$ ' represents statistical difference $(\mathrm{p}<0.001)$ from normal group I, whereas ' $c$ ' represents statistical difference $(p<0.001)$ from INH/RFP-induced group II. Liver tissues were stained with H\&E for pathological verification and viewed at $100 \times$ magnification

induced rat immune-histochemical results. This may be related to the proliferation of inflammatory-activating cytokines TNF- $\alpha$, IL-1 $\beta$, and IL-6 in rat INH / RFP-induced serum ELISA results [11,12]. These results have been supported by previous studies on experimental models of INH / RFP, which lead to oxidative stress and inflammation. Histopathological results also showed that wortmannin can inhibit lipid peroxidation in liver cell membranes and maintain cell boundaries and sinus curves. When liver tissue is structurally damaged, liver enzymes AST, ALT, and ALP usually enter the bloodstream. The presence of high serum liver enzyme concentrations indicates high liver damage, which is similar to the results only in the INH / RFP treatment group. According to histopathology results, wortmannin can significantly inhibit the structural destruction of liver cells and thereby reduce the release of liver enzymes into the blood [13-15]. The presence of inflammatory cells in INH / RFP-induced mouse histopathology departments indicates the presence of an inflammatory response that justifies ELISA results.

In INH / RFP-induced rat immune clotting results, expression of the anti-apoptotic signaling protein PI3K / Akt was inhibited. Treatment with wortmannin significantly alters the apoptotic response by increasing the expression of the PI3K / Akt protein. Other researchers have reported similar results, emphasizing the importance of this control route in preventing severe INH / RFP-induced liver injury. Nrf2 / HO-1 is another important method of preventing oxidative stress and inflammation induced by INH / RFP. The Nfr2 and HO-1 gene play a key role in regulating antioxidant enzymes and protecting against oxidative stress and inflammation. The Nrf2-ARE route is a potential therapeutic target in the pathophysiology of liver damage by preventing oxidative stress and inflammation $[16,17]$. The activation of the Nrf2ARE pathway regulates specific genes that regulate antioxidant defenses such as glutamatecysteine ligase, swardoxin-1, and glutathione peroxidase-2. In addition to activation, it has anti-inflammatory and antioxidant effects on the stress response of the HO-1 gene, thereby protecting against ROS and oxidative stress. The Nrf2 pathway regulates glutathione metabolism and antioxidant response by activating Trx1PI3K / Akt-HIF1-HO-1 / Cyclin D1, thereby preventing liver damage from oxidative stress and inflammation. They are common PI3K / Akt regulators in cell proliferation and have signal transduction in the Nrf2 / HO-1 flow direction, which can prevent oxidative damage and inflammation. Activation of the Keap1 / Nrf2ARE pathway means that it negatively regulates 
anti-inflammatory cytokines, inflammatory mediators, their release factors, and apoptosis mediators, thereby directly or indirectly inhibiting NF-k $\beta$ and MAPK in the early stages of inflammation.

Western Blot results showed that protein expression of atomic Nrf2 and HO-1 was reduced in PI3K / Akt, Nrf2, and HO-1 phosphorylation in INH / RFP-induced mice, while wortmannin was able to regulate protein expression $[18,19]$. According to the results of this study, the hypothesis includes the pathophysiology of INH / RFP-induced liver injury. The INH / RFP treatment group showed inactivation of the PI3K / Akt / Nrf2 / HO-1 pathway, although the NF-k $\beta$ pathway may have been activated because pro-inflammatory cytokines and stress markers are oxidized compared to the normal control group. Expression in groups increased significantly. Increased GSH expression, inhibition of antioxidant enzymes, and inhibition of pro-inflammatory cytokines in the wortmannin treatment group showed an increase in the expression of the PI3K / Akt / Nrf2 / HO-1 protein. These results are consistent with the results of other researchers [20-22]. Therefore, activation of the PI3K / Akt / Nrf2 / HO-1 signaling pathway can prevent severe INH / RFP-induced liver injury in mice. However, further pharmacokinetic studies on the treatment of wortmannin against wort druginduced liver injury need to understand the

\section{REFERENCES}

1. Attri S, Rana SV, Vaiphei K, Sodhi CP, Katyal R, Goel RC, Nain CK, Singh K. Isoniazid- and rifampicin-induced oxidative hepatic injury-protection by $\mathrm{N}$-acetylcysteine. Human Exp. Toxicol. 2000;19(9):517-522. doi:10.1191/ 096032700674230830

2. Darvin SS, Esakkimuthu S, Toppo E, Balakrishna K, Paulraj MG, Pandikumar P, Ignacimuthu S, Al-Dhabi NA. Hepatoprotective effect of lawsone on rifampicinisoniazid induced hepatotoxicity in vitro and in vivo models. Environ. Toxicol. Pharmacol. 2018;61:87-94. doi:10.1016/j.etap.2018.05.006

3. De Rosa HJ, Baldan HM, Brunetti IL, Ximenes VF, Machado RG. The effect of pyrazinamide and rifampicin on isoniazid metabolism in rats. Biopharm. Drug Dispos. 2007;28(6):291-296. doi:10.1002/bdd.557

4. Evan Prince S, Udhaya LB, Sunitha PS, Arumugam G. Reparation of isoniazid and rifampicin combinatorial therapy-induced hepatotoxic effects by Bacopa monnieri. Pharmacology 2016;98(1-2):29-34. doi:10.11 59/000444856

5. He X, Song Y, Wang L, Xu J. Protective effect of pyrrolidine dithiocarbamate on isoniazid/rifampicininduced liver injury in rats. Mol. Med. Rep. 2020;21(1):463-469. doi:10.3892/mmr.2019.10817

6. Hussain T, Subaiea GM, Firdous H. Hepatoprotective Evaluation of Trapa natans against drug-induced potential pathways and specific genes for the protective effect of wortmannin on the liver.

\section{CONCLUSION}

This study concluded that wortmannin showed effective liver protection from acute INH / RFPinduced liver injury. The protective action taken by wortmannin can be demonstrated by activating the PI3K / Akt / Nrf2 / HO-1 signaling pathway to prevent oxidative stress, apoptosis, and inflammation. Increased activity of GSH enzymes/antioxidants inhibits antiinflammatory cytokines and inhibits apoptosisinducing proteins, indicating that wortmannin can activate the Keap 1 / Nrf2-ARE pathway, thereby inhibiting NFkB. Furthermore, histopathology results showed the level of liver protection of wortmannin against INH / RFPinduced liver injury. Therefore, this study demonstrated the potential of wortmanin as a potential candidate for improving liver disease. Further research is needed to determine the therapeutic efficacy of wortmannin as an adjunct.

\section{ACKNOWLEDGEMENTS}

Authors wish to thank Association of Pharmacy Professionals Research Grant Division (APPRGD) for providing financial assistance for this research project through APP Research \& Publication Grant Award 2019 with Grant No. ARPG-19/02-12.04-IUC.

hepatotoxicity of antitubercular agents in rats. Pharmacogn. Mag. 2018;14(54):180-185. doi:10.4103/ pm.pm_237_17

7. Jatav SK, Kulshrestha A, Zacharia A, Singh N, Tejovathi G, Bisen PS, Prasad GBKS. Spirulina maxima protects liver from isoniazid and rifampicin drug toxicity. J. Evid. Based Complementary Altern. Med. 2014;19(3):189-194. doi:10.1177/2156587214530720

8. Martin SJ, Baskaran UL, Vedi M, Sabina EP. Attenuation of anti-tuberculosis therapy induced hepatotoxicity by Spirulina fusiformis, a candidate food supplement. Toxicol. Mech. Methods 2014;24(8):584-592. doi:10.31 09/15376516.2014.956910

9. Nwidu LL, Oboma YI. Telfairia occidentalis (Cucurbitaceae) pulp extract mitigates rifampicinisoniazid-induced hepatotoxicity in an in vivo rat model of oxidative stress. J. Integr. Med. 2019;17(1):46-56. doi:10.1016/j.joim.2018.11.008

10. Nwidu LL, Teme RE. Hot aqueous leaf extract of Lasianthera africana (Icacinaceae) attenuates rifampicin-isoniazid-induced hepatotoxicity. J. Integr. Med. 2018;16(4):263-272.

11. Pal R, Rana S, Vaiphei K, Singh K. Effect of different doses of carotenoids in isoniazid-rifampicin induced hepatotoxicity in rats. Trop. Gastroenterol. 2008;29(3): 153-159. 
12. Pal R, Rana SV, Vaiphei K, Singh K. Isoniazid-rifampicin induced lipid changes in rats. Clin. Chim. Acta 2008;389(1-2):55-60. doi:10.1016/j.cca.2007.11.028

13. Pal R, Vaiphei K, Sikander A, Singh K, Rana SV. Effect of garlic on isoniazid and rifampicin-induced hepatic injury in rats. World J. Gastroenterol. 2006;12(4):636639. doi:10.3748/wjg.v12.i4.636

14. Parameswari SA, Chetty CM, Chandrasekhar KB. Hepatoprotective activity of Ficus religiosa leaves against isoniazid+rifampicin and paracetamol induced hepatotoxicity. Pharmacognosy Res. 2013;5(4):271-276. doi:10.4103/0974-8490.118828

15. Pingili RB, Challa SR, Pawar AK, Toleti V, Kodali T, Koppula S. A systematic review on hepatoprotective activity of quercetin against various drugs and toxic agents: Evidence from preclinical studies. Phytother. Res. 2020;34(1):5-32. doi:10.1002/ptr.6503

16. Prabakan M, Anandan R, Devaki T. Protective effect of Hemidesmus indicus against rifampicin and isoniazidinduced hepatotoxicity in rats. Fitoterapia 2000;71(1):55-59. doi:10.1016/s0367-326x(99)001203

17. Rana SV, Pal R, Vaiphie K, Singh K. Effect of different oral doses of isoniazid-rifampicin in rats. Mol. Cell. Biochem. 2006;289(1-2):39-47. doi:10.1007/s11010006-9145-3
18. Saad EI, El-Gowilly SM, Sherhaa MO, Bistawroos AE. Role of oxidative stress and nitric oxide in the protective effects of alpha-lipoic acid and aminoguanidine against isoniazid-rifampicin-induced hepatotoxicity in rats. Food Chem. Toxicol. 2010;48(7):1869-1875. doi:10.1016/j.fct.2010.04.026

19. Sabina EP, Jerine Peter S, Prathap S, Geetha A. A comparison of hepatoprotective activity of bacoside to silymarin treatment against a combined isoniazid and rifampin-induced hepatotoxicity in female wistar rats. $J$. Histotechnol. doi:10.1080/01478885.2019.1638535

20. Sanjay S, Girish C, Toi PC, Bobby Z. Quercetin modulates Nrf2 and NF- $\kappa B / T L R-4$ pathways to protect against isoniazid and rifampicin induced hepatotoxicity in vivo. Can. J. Physiol. Pharmacol. 2021 (Epub ahead of print); doi:10.1139/cjpp-2021-0008

21. Sankar M, Rajkumar J, Devi J. Hepatoprotective activity of hepatoplus on isonaizid and rifampicin induced hepatotoxicity in rats. Pak. J. Pharm. Sci. 2015;28(3):983-990.

22. Sankar M, Rajkumar J, Sridhar D. Hepatoprotective activity of heptoplus on isoniazid and rifampicin induced liver damage in rats. Indian J. Pharm. Sci. 2015;77(5):556-562. doi:10.4103/0250-474x.16902 